\title{
Changes in Bull Semen Metabolome in Relation to Cryopreservation and Fertility
}

\author{
Valentina Longobardi ${ }^{1}$, Michal A. Kosior ${ }^{2}$, Nunzia Pagano ${ }^{2}$, Gerardo Fatone ${ }^{2, *}$ (]), \\ Alessia Staropoli ${ }^{3}$, Anastasia Vassetti ${ }^{3}$, Francesco Vinale ${ }^{2,3} \mathbb{D}$, Giuseppe Campanile ${ }^{2}$ (D) and \\ Bianca Gasparrini ${ }^{2}$ \\ 1 Department of Precision Medicine, University of Campania Luigi Vanvitelli, 80138 Naples, Italy; \\ longobardivalentina@gmail.com \\ 2 Department of Veterinary Medicine and Animal Production, Federico II University of Naples, 80137 Naples, \\ Italy; m.kosior@hotmail.com (M.A.K.); nunzia91n@libero.it (N.P.); francesco.vinale@ipsp.cnr.it (F.V.); \\ giucampa@unina.it (G.C.); bgasparr@unina.it (B.G.) \\ 3 CNR Institute for Sustainable Plant Protection, 80055 Portici, Italy; al.staropoli@gmail.com (A.S.); \\ an.vassetti@libero.it (A.V.) \\ * Correspondence: gerardo.fatone@unina.it
}

Received: 1 June 2020; Accepted: 17 June 2020; Published: 19 June 2020

Simple Summary: Although semen cryopreservation has facilitated the diffusion of artificial insemination and in vitro fertilization in cattle, it still represents a major factor affecting sperm fertility. It is known that cryopreservation induces the loss of fertility-associated proteins, while the effect on metabolites has not been evaluated, although several compounds affect sperm physiology and fertility. The aim of the present work was to study the metabolome in bovine sperm and seminal plasma after cryopreservation and to correlate the metabolic profile of high- and low-fertility bulls in order to identify fertility markers. The analysis, carried out by liquid chromatography-mass spectrometry methods, revealed differences in metabolite contents between fresh and cryopreserved semen, both at cellular and plasmatic levels. Interestingly, metabolites showing variation have important functions related to fertility. In addition, the study highlighted the differences in lipid profile between high- and low-fertility bulls. The identification of new potential fertility markers is of high economic impact. In addition, it opens the way for the development of corrective strategies to improve the fertility of low-fertility bulls.

Abstract: Semen cryopreservation determines several sperm damages, including the loss of fertility-associated proteins. The purpose of the study was to compare the metabolite contents in bovine sperm and seminal plasma before and after cryopreservation, and between high- and low-fertility bulls in vitro. Forty-eight ejaculates, collected from eight bulls (six per bull), were analyzed by liquid chromatography-mass spectrometry. Cryopreservation resulted in an over-expression of lysophosphatidylcholine $(0: 0 / 18: 2(9 \mathrm{Z}, 12 \mathrm{Z}))$ in seminal plasma. In addition, higher levels of glycine betaine and pyro-L-glutaminyl-L-glutamine were observed in cryopreserved compared to fresh spermatozoa. The fresh seminal plasma of high-fertility bulls showed an over-expression of L-acetylcarnitine, glycerol tripropanoate, 2,3-diacetoxypropyl stearate and glycerophosphocholine, and an under-expression of lysophosphatidylcholine and butyrylcarnitine, compared to low-fertility bulls. Higher levels of glycerophosphocholine and lysophosphatidylcholine (16:0/0:0) were recorded in fresh spermatozoa from high-fertility bulls. In high-fertility bulls, a greater content of glycerophosphocholine and lower levels of butyrylcarnitine, glycine betaine and L-carnitine were found in cryopreserved seminal plasma, and lower levels of glycine betaine were detected in cryopreserved spermatozoa. In conclusion, cryopreservation affects bovine semen metabolome at both plasmatic and cellular compartments, and metabolic profile differs between high- and low-fertility bulls. 
Keywords: fertility; bull; LC-MS; cryopreservation; metabolites

\section{Introduction}

Fertility is a major factor influencing the sustainability of livestock breeding. It is known that reproductive failure in cattle is in great part due to the poor fertilizing ability of sperm $[1,2]$. Semen cryopreservation has played a fundamental role in spreading the use of advanced reproductive technologies, such as artificial insemination (AI) and in vitro fertilization (IVF) in cattle. Nevertheless, cryopreservation is an important factor affecting sperm fertility. Indeed, freezing-thawing can induce several sperm damages [3], the premature capacitation of spermatozoa $[4,5]$ and the loss of fertility-associated molecules [6,7]. Indeed, it is known that freezing-thawing induces the leakage of proteins, especially enzymes, from inside the spermatozoa to the extracellular fluid $[8,9]$. In addition, it was demonstrated that the proteomic profile of bovine seminal plasma is affected by cryopreservation [10].

Another important limiting factor is the bull effect (i.e., the high individual variability in fertilizing ability recorded among bulls) [6,11]. Despite an adequate production of motile and morphologically normal sperm, some bulls have low fertility, whose molecular mechanisms are not known [12]. Therefore, the ability to predict bull fertility in advance offers enormous benefits for the economic success of livestock enterprise by improving pregnancy rates [13]. Currently, the assessment of bull fertility still relies on several fertility tests, including motility, viability and morphology; however, while these conventional analyses allow for the detection of unsuitable ejaculates, they often fail to accurately predict real fertility.

Metabolomics characterizes the downstream of biology systems and has been recently applied to study reproductive processes [14-16]. This approach allows for the comprehensive identification of metabolites, such as amino acids, peptides, fatty acids and carbohydrates in secretions, cells, tissues and organs [17-19]. Metabolomics has been recently used to identify male fertility biomarkers in farm animals, including cattle $[20,21]$. Seminal plasma has long been used as a key source to investigate male infertility. The metabolites of seminal plasma can affect many aspects of sperm physiology and influence bull fertility, by changing gene and protein expression [22]. Metabolomic profiling has been used to identify potential fertility biomarkers in the seminal plasma of bulls [15] and men [14]. In cattle, the analysis of seminal plasma by gas chromatography-mass spectrometry (GC-MS) allowed for the identification of sixty-three metabolites [21]. In the same study, a higher concentration of 2-oxoglutaric acid and fructose were found in bulls classified as high-fertile, suggesting the potential use of metabolites as biomarkers of bull fertility [21]. A variety of techniques, such as mass spectrometry, nuclear magnetic resonance spectroscopy, and Fourier transform infrared spectroscopy, are available in metabolomics at present [19]. Among them, liquid chromatography-mass spectrometry (LC-MS) has already been used in metabolomics studies of seminal plasma in humans [23].

To our knowledge, the variation in metabolite contents following semen cryopreservation has still not been investigated in cattle. Metabolites are reliable indicators of phenotypic traits, as they are the end products of metabolic pathways [15]. The identification of fertility-associated metabolites can open the way for the development of corrective strategies, by reintegrating key compounds lost during cryopreservation to restore the fertility of cryopreserved semen.

The aim of this study was to evaluate the differences in the metabolites present in seminal plasma and spermatozoa between fresh and cryopreserved bovine sperm by a metabolomic approach (LC-MS). A further objective of this work was to compare the metabolomes of seminal plasma and spermatozoa of high-fertility (HF) and low-fertility (LF) bulls, as assessed in vitro, to identify new reliable fertility markers. 


\section{Materials and Methods}

\subsection{Experimental Design}

In this work both the seminal plasma and spermatozoa of fresh and cryopreserved semen were analyzed. Eight healthy Holstein (Bos Taurus) bulls (4-6 years of age), maintained at an authorized National Semen Collection Center (Centro Tori Chiacchierini, Civitella D'Arna, Perugia, Italy; authorization numbers: PG0001C for Italy and IT014 for Europe), under uniform management conditions and routinely used for semen collection, were selected for the trial. For this study, a total of forty-eight ejaculates were collected weekly from eight bulls (six ejaculates per bull) by artificial vagina (IMV, L'Aigle, France). On fresh semen, motility was evaluated by phase contrast microscopy and only ejaculates containing more than $80 \%$ motile sperm were used in the study. After the initial semen assessment (volume, concentration and motility), each ejaculate was split into two aliquots. An aliquot was centrifuged ( $3000 \mathrm{rpm}$ for $10 \mathrm{~min}$, at $25^{\circ} \mathrm{C}$ ) to separate seminal plasma and spermatozoa and were immediately processed for analysis (fresh seminal plasma and spermatozoa, termed F-P and F-S groups, respectively). The other aliquot was cryopreserved by standard method with commercial extender BioXcell (IMV-technologies, L'Aigle France), to have a final concentration of $30 \times 10^{6}$ spermatozoa per $\mathrm{mL}$ in $0.5 \mathrm{~mL}$ French straws, which underwent combined cooling with an equilibration period of $3 \mathrm{~h}$ at $5{ }^{\circ} \mathrm{C}$. The straws were kept in an automatic programmable biological cell freezer (IMV technology, France) until the temperature of straws reached $-145^{\circ} \mathrm{C}$. Then, the straws were plunged into liquid nitrogen $\left(-196{ }^{\circ} \mathrm{C}\right)$ for storage. The straws were thawed at $37^{\circ} \mathrm{C}$ for $40 \mathrm{~s}$ in a water bath, and the seminal plasma and spermatozoa were separated by centrifugation ( $3000 \mathrm{rpm}$ for $10 \mathrm{~min}$, at $25^{\circ} \mathrm{C}$ ) and stored at $-20^{\circ} \mathrm{C}$ (for approximately two months) until further analysis (cryopreserved seminal plasma and spermatozoa, termed CRY-P and CRY-S groups, respectively). In order to distinguish HF and LF bulls, sperm viability, morphology, membrane integrity, DNA fragmentation, as well as in vitro fertilizing ability, were evaluated after thawing.

\subsection{Assessment of Fertility Parameters}

Cryopreserved semen straws from the same ejaculates $(n=48)$ used for metabolite extraction were thawed and utilized for the assessment of sperm viability, morphology, membrane integrity and DNA fragmentation. Cleavage and blastocyst rates were evaluated after in vitro fertilization with frozen-thawed spermatozoa from three randomly selected ejaculates/bull $(n=24)$.

Sperm viability (percentage of acrosome intact live sperm) and morphology were assessed by the Trypan Blue/Giemsa technique, as previously described [5]. The functional integrity of the sperm was assessed by the Hypo osmotic swelling (HOS) test [5] and expressed as the percentage of sperm showing swollen tails (HOS+ sperm) following incubation in a hypoosmolar solution of $150 \mathrm{mOsm} / \mathrm{L}$. DNA fragmentation index was assessed by Tunel assay [24] using a commercially available kit (In Situ Cell Death Detection Kit, Roche, Indianapolis, IN, USA). The sperm were analyzed by using a fluorescent microscope (Eclipse E-600; Nikon, Japan) under ultraviolet light with excitation DAPI (460 $\mathrm{nm}$ for blue fluorescence), and FITC (520 $\mathrm{nm}$ for green fluorescence) filters and the numbers of total (blue) and Tunel-positive (green) nuclei were recorded. At least 200 spermatozoa were analyzed for viability, membrane integrity and DNA fragmentation assessments.

To assess in vitro fertilizing ability, abattoir-derived bovine oocytes were matured and fertilized in vitro with frozen-thawed sperm from different bulls, then cultured in vitro to the blastocyst stage, according to our standard procedure [25]. Briefly, cumulus-oocyte complexes (COCs) were aspirated from follicles of 2-8 $\mathrm{mm}$ in diameter and only those with uniform cytoplasm and multilayered cumulus cells were matured in TCM 199, supplemented with $15 \%$ bovine serum (BS), $0.5 \mu \mathrm{g} / \mathrm{mL} \mathrm{FSH,} 5 \mu \mathrm{g} / \mathrm{mL}$ LH, $0.8 \mathrm{mM} \mathrm{L}$-glutamine and $50 \mu \mathrm{g} / \mathrm{mL}$ gentamycin $(25-30 \mathrm{COCs} / 400 \mu \mathrm{L})$ in four well plates (NuncTM, Roskilde, Denmark) for $22 \mathrm{~h}$ at $39{ }^{\circ} \mathrm{C}$ and $5 \% \mathrm{CO}_{2}$ in the air. In vitro, matured COCs were washed and transferred into $300 \mu \mathrm{L}$ of Tyrode's modified medium without glucose and bovine serum albumin (BSA), supplemented with $5.3 \mathrm{SI} / \mathrm{mL}$ heparin, $30 \mu \mathrm{M}$ penicillamine, $15 \mu \mathrm{M}$ hypotaurine, $1 \mu \mathrm{M}$ epinephrine 
and 1\% BS (IVF medium). The sperm selected by BoviPure gradients (according to the manufacturer's instructions, Nidacon, Sweden) were diluted with IVF medium and added in the fertilization wells at a concentration of $1 \times 10^{6} \mathrm{sperm} / \mathrm{mL}$. Gametes were co-incubated for $20 \mathrm{~h}$ at $39{ }^{\circ} \mathrm{C}$ in $5 \% \mathrm{CO}_{2}$ in the air, after which presumptive zygotes were vortexed for $2 \mathrm{~min}$ to remove cumulus cells in Hepes-TCM with $5 \%$ BS, washed twice in the same medium and randomly distributed into $400 \mu \mathrm{L}$ Synthetic Oviduct Fluid (SOF) medium with $30 \mu \mathrm{L} / \mathrm{mL}$ essential amino acids, $10 \mu \mathrm{L} / \mathrm{mL}$ nonessential amino acids and $5 \%$ BS and incubated in a humidified mixture of $5 \% \mathrm{CO}_{2}, 5 \% \mathrm{O}_{2}$ and $88 \% \mathrm{~N}_{2}$ in the air at a temperature of $39^{\circ} \mathrm{C}$. The cleavage and blastocyst rates, calculated out of the total COCs, were recorded, respectively, on days two and seven after in vitro fertilization.

\subsection{Metabolite Extraction}

Metabolites extraction was performed by adding $900 \mu \mathrm{L}$ methanol to $300 \mu \mathrm{L}$ seminal plasma, vortexed for $1 \mathrm{~min}$ and stored at $-20{ }^{\circ} \mathrm{C}$ for $2 \mathrm{~h}$, in order to precipitate the proteins. The samples were then centrifuged at $12,000 \mathrm{rpm}$ for $15 \mathrm{~min}$ at $4{ }^{\circ} \mathrm{C}$ and the supernatant was filtered with $0.22 \mu \mathrm{m}$ membrane syringe filters. Spermatozoa were lysed in methanol according to a protocol previously described [26], consisting briefly in eight long-lasting pulses of $100 \%$ amplitude and $10 \mathrm{kHz}$ in a sonicator Vibra-Cell ${ }^{\mathrm{TM}}$ (Sonics \& Materials, Inc., Newtown, CT, USA). To avoid specimen heating, the samples were kept on ice while sonicating. Following this step, the samples were kept on ice for a further $30 \mathrm{~min}$ and then the same protocol used for seminal plasma was followed. Unless otherwise stated, the reagents were purchased from Merck/Sigma-Aldrich (Milano, Italy).

\subsection{LC-MS Analysis}

Analyses were done on an Agilent high performance liquid chromatograph (HPLC) 1260 Infinity Series (Agilent Technologies, Santa Clara, CA, USA) equipped with a DAD (Diode Array Detector) system (Agilent Technologies) and coupled to a quadrupole-time of flight (Q-TOF) mass spectrometer model G6540B (Agilent Technologies) with a Dual ESI source (Agilent Technologies). The column used for separation was an Ascentis ${ }^{\circledR}$ Express C-18 column $(2.7 \mu \mathrm{m}, 50 \mathrm{~mm} \times 3.0 \mathrm{~mm}$ i.d., Supelco@), Bellefonte, PA, USA), held at a constant temperature of $40^{\circ} \mathrm{C}$. The mobile phase consisted of A: $0.1 \%$ $(v / v)$ formic acid (FA) in water $\left(\mathrm{H}_{2} \mathrm{O}\right)$ and $\mathrm{B}: 0.1 \%$ formic acid (FA) in acetonitrile (ACN). Elution was done at a flow rate of $0.6 \mathrm{~mL} / \mathrm{min}$ and the gradient was as follows: starting condition $5 \% \mathrm{~B}$, held for $1.10 \mathrm{~min}$, ramping to $95 \%$ B until $9.30 \mathrm{~min}$, held at $95 \%$ B for $1.10 \mathrm{~min}$, lowering to $5 \% \mathrm{~B}$ in $2.30 \mathrm{~min}$, and $5 \% \mathrm{~B}$ for $3 \mathrm{~min}$ as equilibration time. The injection volume was $4 \mu \mathrm{L}$. UV spectra were collected by DAD, setting the detection wavelength at 210, 250 and $280 \mathrm{~nm}$. Both HPLC and MS and their parameters were set using the Agilent MassHunter Data Acquisition Software, rev. B.05.01 (Agilent Technologies). The system operated in positive ion mode and MS spectra were recorded in the $m / z \mathbf{t} 50-1000$ range as centroid spectra, with a speed of 3.3 spectra/s. The capillary was maintained at $2000 \mathrm{~V}$, fragmentor voltage at $180 \mathrm{~V}$, cone 1 (skimmer 1) at $45 \mathrm{~V}$ and Oct RFV at $750 \mathrm{~V}$. The gas flow rate was set at $11 \mathrm{~L} / \mathrm{min}$ at $350{ }^{\circ} \mathrm{C}$ and the nebulizer was set at $45 \mathrm{psig}$. A standard solution was infused by using an Isocratic pump (1260 Infinity Series, Agilent Technologies) in order to perform the real-time lock mass correction. The solution consisted of two reference mass compounds: purine $\left(\mathrm{C}_{5} \mathrm{H}_{4} \mathrm{~N}_{4}\right.$ at $m / z$ 121.050873, $\left.10 \mu \mathrm{mol} / \mathrm{L}\right)$ and hexakis $(1 \mathrm{H}, 1 \mathrm{H}, 3 \mathrm{H}$-tetrafluoropentoxy)-phosphazene $\left(\mathrm{C}_{18} \mathrm{H}_{18} \mathrm{O}_{6} \mathrm{~N}_{3} \mathrm{P}_{3} \mathrm{~F}_{24}\right.$ at $\mathrm{m} / z$ 922.09798, $\left.2 \mu \mathrm{mol} / \mathrm{L}\right)$. The flow rate was set at $0.06 \mathrm{~mL} / \mathrm{min}$, while the detection window and the minimum height were set at 1000 ppm and 10.000 counts, respectively, for reference mass correction.

\section{LC-MS Raw Data Analysis}

Data from the LC-MS analysis were first subjected to the extraction of peak components and to chromatographic alignment, performed by using MassHunter Profinder, version 06.00. The batch recursive feature extraction was used to extract and align the molecular features in all biological and analytical replicates for each group of samples. The parameters for molecular feature extraction 
included a peak height of $\geq 5000$ counts and the extraction of possible ions inclusive of the protonated ion, or the sodiated adduct. At least two ions were required for a single molecular feature. For binning and alignment, a tolerance of $0.3 \mathrm{~min}$ and $20 \mathrm{ppm}$ was set for the retention time window and mass window, respectively. The post-processing filters applied included the requirement for the molecular feature to be present in at least three out of six replicates in one group.

\subsection{Statistical Analysis}

Statistical analysis was carried out using Mass Profile Professional, version 13.1.1 (Agilent Technologies). Aligned data on seminal plasma and spermatozoa from fresh (F-P and F-S, respectively), and cryopreserved (CRY-P and CRY-S, respectively) groups were filtered based on the quality of their presence (present-marginal-absent) in the samples and conditions. After this operation, only entities in which at least $100 \%$ of the values in any one of two conditions have acceptable values, were retained. The remaining entities were further filtered based on their frequency of occurrence among the samples and conditions. In particular, only entities that appeared in at least $100 \%$ of the samples, in at least one condition, were retained. An unpaired Student $t$-test $(p>0.05)$ with Tukey-HSD post hoc and Benjamini-Hochberg correction was applied to assess the differential significance of samples. Eventually, fold change $>2.0$ was applied. The results obtained were then subjected to principal components analysis (PCA) and hierarchical clustering in order to compare the metabolome of seminal plasma and spermatozoa between HF and LF bulls to detect differences in metabolome induced by the cryopreservation.

Statistically relevant compounds were identified using the freely available electronic database, Human Metabolome database (HMDB) and by comparison with standard compounds or with data present in the literature. Among the detected molecules, only those with a mass error below $10 \mathrm{ppm}$ and a sufficient score $(\geq 95 \%)$ were reported.

\section{Results}

\subsection{Metabolomic Analysis of Seminal Plasma before and after Cryopreservation}

The metabolic profile was different between fresh (F-P) and cryopreserved (CRY-P) seminal plasma. The separation is shown in PCA scores plot, as shown in Figure 1. Hierarchical clustering analysis also showed a separation of these groups, related to a different chemical composition, as shown in Figure S1. In particular, a putatively identified metabolite was under-expressed in the F-P samples, as shown in Table 1.

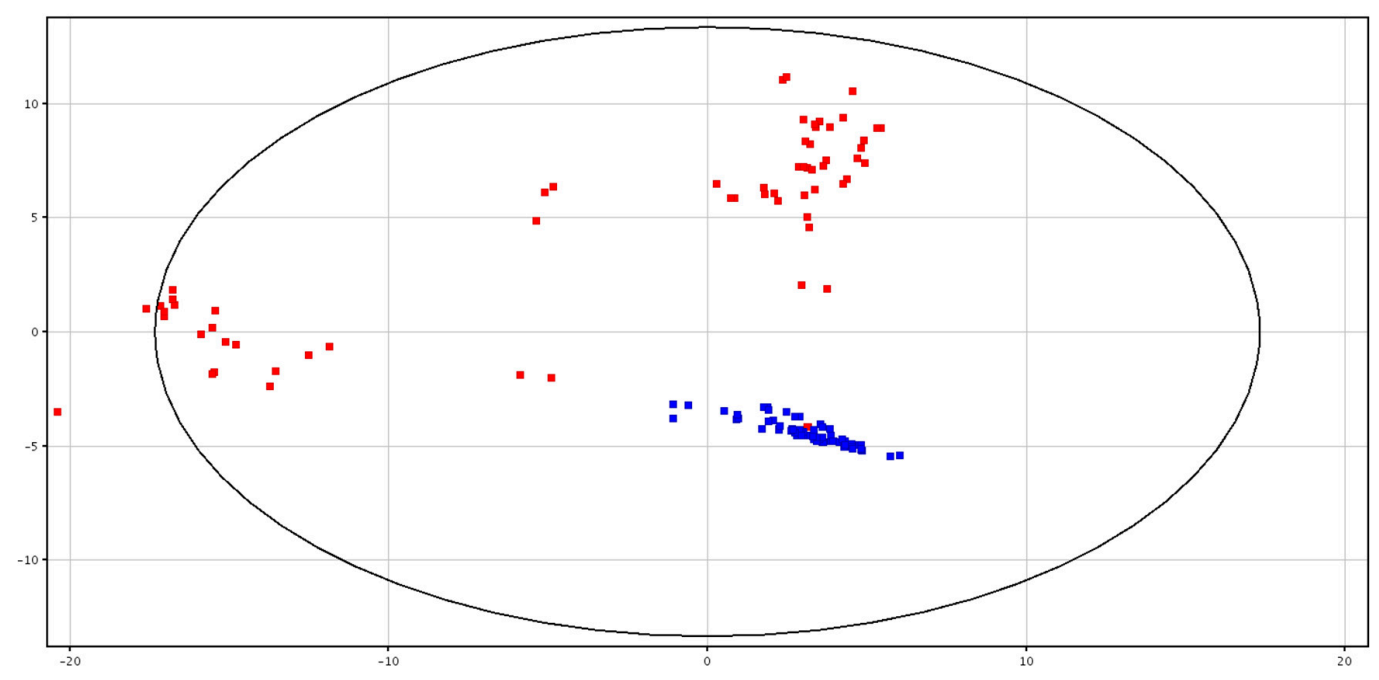

Figure 1. PCA scores plots of the LC-MS data acquired for fresh (in blue; F-P) and cryopreserved (in red; CRY-P) seminal plasma. PC1 ( $x$-axis) is $37.3 \%$; PC2 ( $y$-axis) is $22.22 \%$. 
Table 1. Values of $p$ Corrected and Log2Fold Change of putatively identified metabolites in fresh and cryopreserved seminal plasma (F-P and CRY-P) and fresh and cryopreserved spermatozoa (F-S and, CRY-S) samples ( $t$-test with $p$-value $<0.05$ and fold change $>2.0$ ).

\begin{tabular}{cccccc}
\hline & & \multicolumn{2}{c}{ F-P vs. CRY-P } & \multicolumn{2}{c}{ F-S vs. CRY-S } \\
\hline Compound & Mass (Da) & Log2FC & $p$ Corr & Log2FC & $p$ Corr \\
\hline $\begin{array}{c}\text { Glycine Betaine } \\
\text { a }\end{array}$ & 117.0789 & & & 1.68 & $3.43 \times 10^{-2}$ \\
LysoPC (0:0/18:2(9Z,12Z)) $^{*}$ a & 519.334 & 1.54 & $1.34 \times 10^{-31}$ & & \\
Pyro-L-glutaminyl-L-glutamine a $^{\text {a }}$ & 257.1015 & & & 1.26 & $3.49 \times 10^{-2}$ \\
\hline
\end{tabular}

${ }^{*}$ LysoPC (0:0/18:2(9Z,12Z)) lysophosphatidylcholine (0:0/18:2(9Z,12Z)). ${ }^{a}$ Down-regulation against CRY group; blank cells mean the metabolite was not statistically different.

\subsection{Metabolomic Analysis of Spermatozoa before and after Cryopreservation}

Differences between fresh and cryopreserved spermatozoa were detected, as shown in Figure 2. Clustering for the two groups showed the total variance within the PCA data, as shown in Figure S2. In particular, two putatively identified metabolites (i.e., glycine betaine and pyro-L-glutaminyl-L-glutamine), were higher in content in the cryopreserved samples, as shown in Table 1.

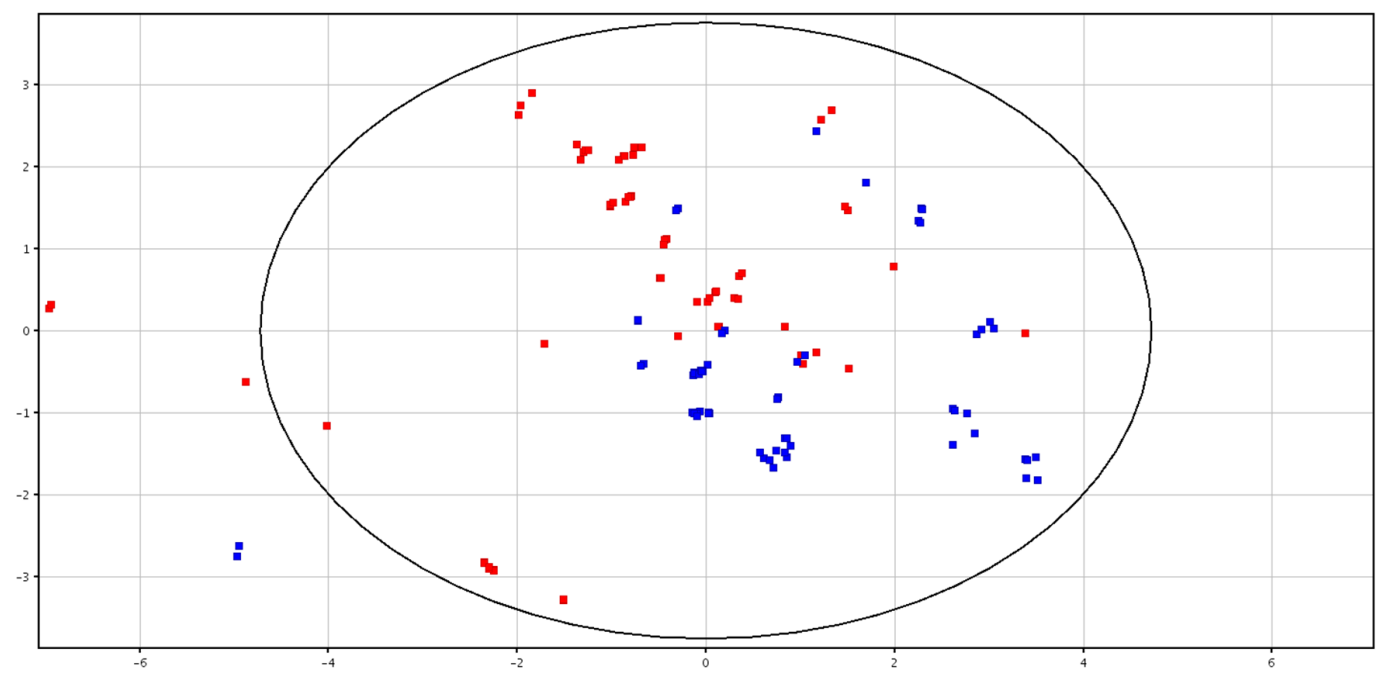

Figure 2. PCA scores plots of the LC-MS data acquired for fresh (in blue; F-S) and cryopreserved (in red; CRY-S) spermatozoa. PC1 ( $x$-axis) is $32.23 \%$; PC2 (y-axis) is $20.35 \%$.

\subsection{Metabolomic Analysis of Seminal Plasma from HF and LF Bulls}

The fertility-associated parameters of HF and LF bulls are shown in Table 2.

Table 2. Post-thawing morphological and functional sperm parameters in high fertility (HF, $n=4)$, and low fertility (LF, $n=4)$ bulls.

\begin{tabular}{|c|c|c|}
\hline Parameters & HF $($ Mean \pm SE) & LF $($ Mean \pm SE) \\
\hline Viability $(\%) *$ & $80.0 \pm 2.0^{\mathrm{A}}$ & $46.7 \pm 6.7^{B}$ \\
\hline Total Anomalies (\%) * & $7.8 \pm 1.3$ & $9.7 \pm 2.5$ \\
\hline $\mathrm{HOS}+(\%) *$ & $67.8 \pm 1.8^{\mathrm{A}}$ & $55.0 \pm 2.4^{\mathrm{B}}$ \\
\hline Tunel $+(\%) *$ & $10.5 \pm 2.2$ & $14.6 \pm 1.9$ \\
\hline Cleavage $(\%)^{* *}$ & $75.3 \pm 1.8^{\mathrm{A}}$ & $54.9 \pm 3.5^{\text {В }}$ \\
\hline Blastocysts (\%) ** & $31.1 \pm 1.8^{\mathrm{A}}$ & $13.4 \pm 2.8^{\text {B }}$ \\
\hline
\end{tabular}

\footnotetext{
$\mathrm{A}, \mathrm{B}$ Values within columns with different superscripts are significantly different; $p<0.01 .{ }^{*}$ Parameters were assessed on six ejaculates/bull ( $n=48$ ejaculates). ${ }^{* *}$ In vitro fertilization was carried out with three randomly selected ejaculates/bull $(n=24)$.
} 
Principal Component Analysis (PCA)and hierarchical clustering showed a distinct separation between HF and LF bulls, according to the metabolic content in fresh and cryopreserved seminal plasma, as shown in Figures 3 and 4 and Figures S3 and S4. All of the identified metabolites are reported in Table 3. High-fertility bulls showed higher levels of L-acetylcarnitine, glycerol tripropanoate, 2,3-diacetoxypropyl stearate and glycerophosphocholine (GPC), and lower levels of butyrylcarnitine, lysoPC (P-16:0/0:0) and piperidine in the F-P samples. In the CRY-P samples, higher levels of GPC and lower levels of L-carnitine, butyrylcarnitine and glycine betaine were found in HF bulls.

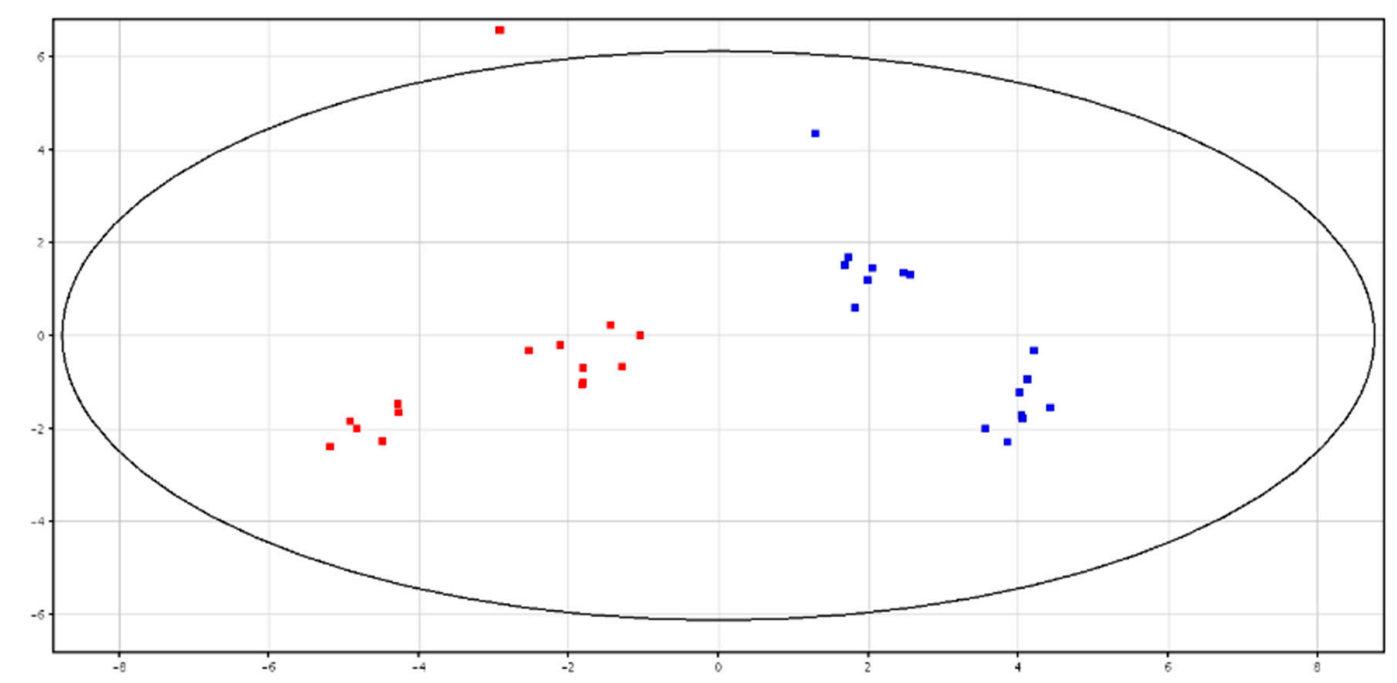

Figure 3. PCA scores plots of the LC-MS data acquired from fresh seminal plasma for high (in red; HF) and low (in blue; LF) fertility bulls. PC1 ( $x$-axis) is $43.77 \%$; PC2 ( $y$-axis) is $21.53 \%$.

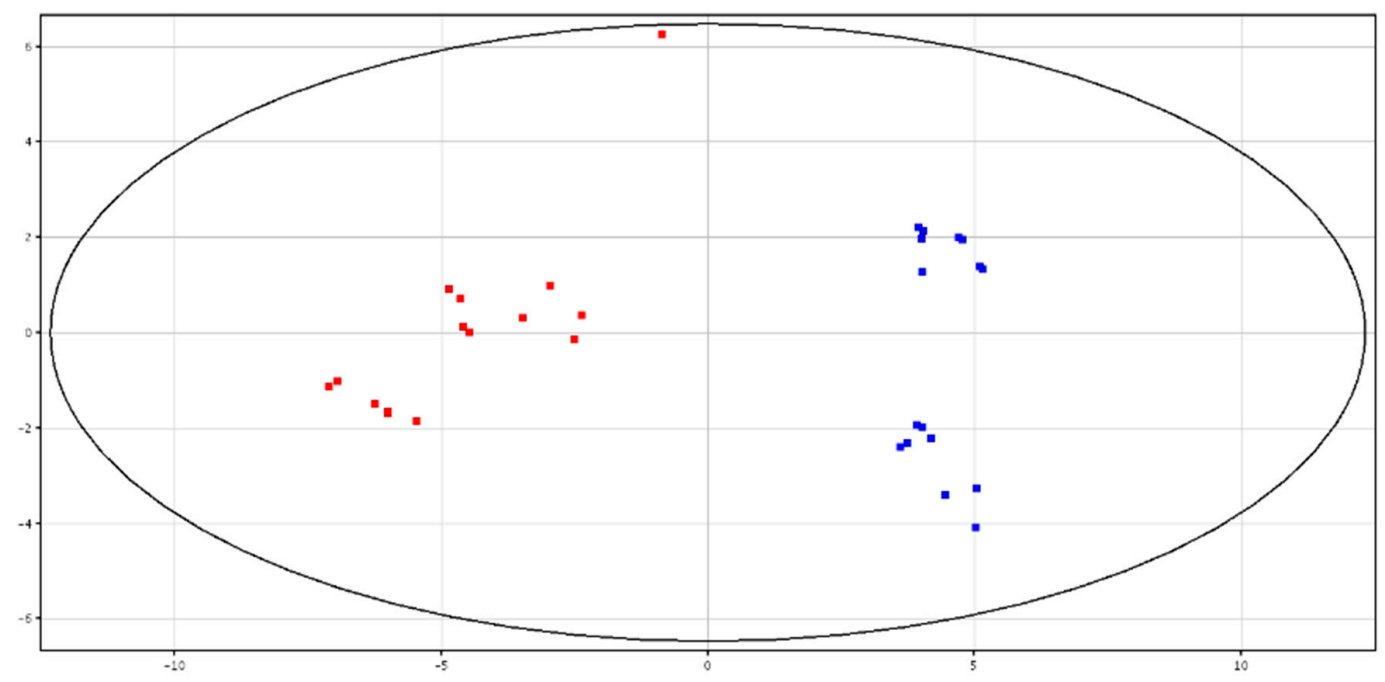

Figure 4. PCA scores plots of the LC-MS data acquired from cryopreserved seminal plasma for high (in red) and low (in blue) fertility bulls. PC1 ( $x$-axis) is 50.89\%; PC2 (y-axis) is $13.96 \%$. 
Table 3. Values of $p$ Corrected and Log2Fold Change of putatively identified metabolites in fresh and cryopreserved seminal plasma (F-P, CRY-P) and spermatozoa (F-S, CRY-S) samples in low and high fertility bulls ( $t$-test with $p$-value $<0.05$ and fold change $>2.0$ ).

\begin{tabular}{|c|c|c|c|c|c|c|c|c|c|}
\hline \multirow[t]{2}{*}{ Compound } & \multirow[t]{2}{*}{ Mass (Da) } & \multicolumn{2}{|c|}{ F-P } & \multicolumn{2}{|c|}{ CRY-P } & \multicolumn{2}{|c|}{ F-S } & \multicolumn{2}{|c|}{ CRY-S } \\
\hline & & $\log 2 \mathrm{FC}$ & $p$ Corr & $\log 2 \mathrm{FC}$ & $p$ Corr & $\log 2 \mathrm{FC}$ & $p$ Corr & $\log 2 \mathrm{FC}$ & $p$ Corr \\
\hline 2,3-Diacetoxypropyl stearate ${ }^{B}$ & 44.3283 & 1.43 & $2.13 \times 10^{-3}$ & & & & & & \\
\hline Glycine Betaine ${ }^{\mathrm{A}}$ & 117.0789 & & & 1.77 & $7.97 \times 10^{-32}$ & & & 1.32 & $1.39 \times 10^{-2}$ \\
\hline Butyrylcarnitine ${ }^{\mathrm{A}}$ & 231.1473 & 1.14 & $7.76 \times 10^{-3}$ & 1.32 & $3.84 \times 10^{-3}$ & & & & \\
\hline Glycerol tripropanoate $^{B}$ & 260.1239 & 1.63 & $8.55 \times 10^{-3}$ & & & & & & \\
\hline GPC $*, B$ & 257.1032 & 1.07 & $1.31 \times 10^{-1}$ & 1.54 & $8.73 \times 10^{-3}$ & 2.23 & $3.95 \times 10^{-3}$ & & \\
\hline L-Acetylcarnitine ${ }^{B}$ & 203.1159 & 1.00 & $6.04 \times 10^{-1}$ & & & & & & \\
\hline L-Carnitine $\mathrm{A}$ & 161.1049 & & & 1.38 & $4.60 \times 10^{-31}$ & & & & \\
\hline LysoPC (16:0/0:0) *,B & 495.3346 & & & & & 2.38 & $1.20 \times 10^{-3}$ & & \\
\hline LysoPC (P-16:0/0:0) *,A & 479.3382 & 2.04 & $1.61 \times 10^{-2}$ & & & & & & \\
\hline Piperidine $\mathrm{A}$ & 85.892 & 1.32 & $1.098 \times 10^{-5}$ & & & & & & \\
\hline
\end{tabular}

group; ${ }^{\mathrm{B}}$ Down-regulation in low- vs. high-fertility group; blank cells mean the metabolite was not statistically different. 


\subsection{Metabolomic Analysis of Spermatozoa from HF and LF Bulls}

Both PCA and hierarchical clustering differentiated HF and LF bulls according to the metabolite contents in fresh and cryopreserved spermatozoa, as shown in Figures 5 and 6 and Figures S5 and S6. All of the identified compounds are reported in Table 3.

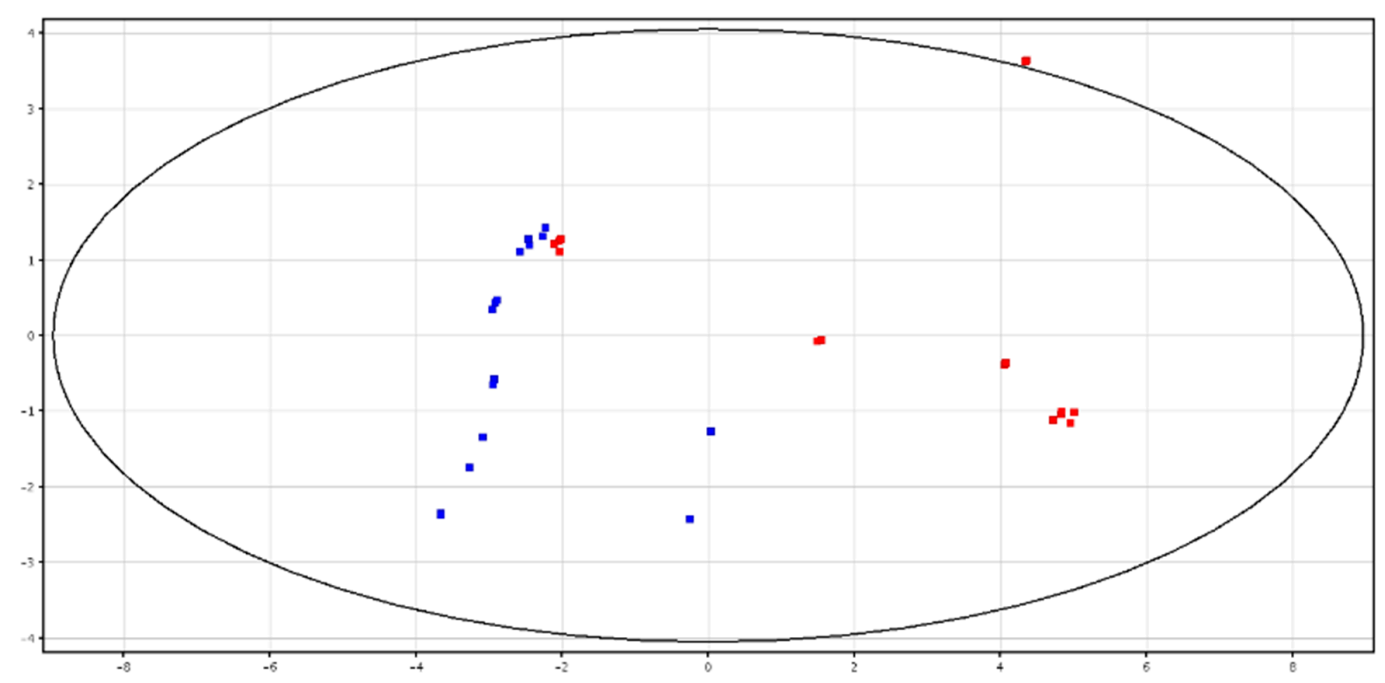

Figure 5. PCA scores plots of the LC-MS data acquired from fresh spermatozoa for high (in red) and low (in blue) fertility bulls. PC1 ( $x$-axis) is $54.94 \%$; PC2 ( $y$-axis) is $13.29 \%$.

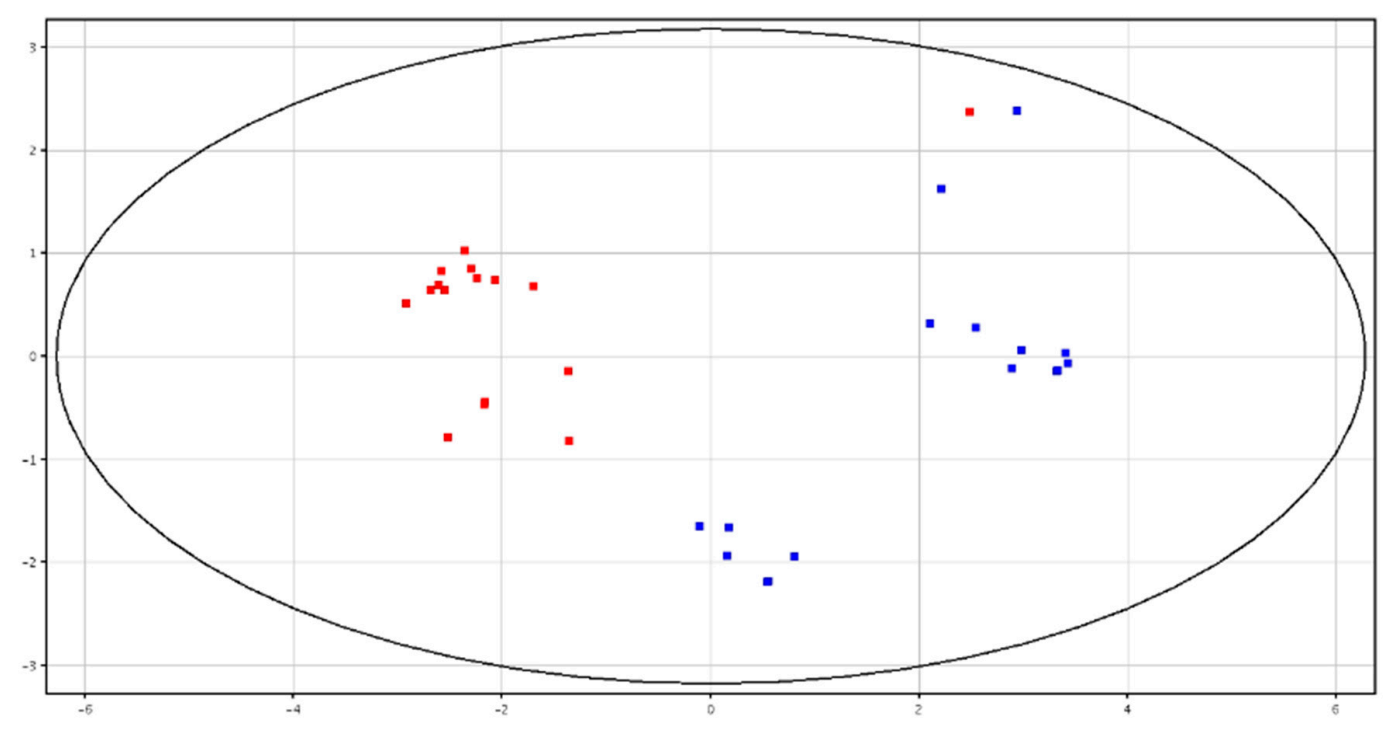

Figure 6. PCA scores plots of the LC-MS data acquired from cryopreserved spermatozoa for high (in red; HF) and low (in blue; LF) fertility bulls. PC1 ( $x$-axis) is $59.92 \%$; PC2 ( $y$-axis) is $15.38 \%$.

\section{Discussion}

This study analyzed, using LC-MS techniques, the changes in metabolite contents in bovine sperm and seminal plasma occurring during cryopreservation. A further objective was to compare the metabolite contents in fresh and cryopreserved sperm and seminal plasma between HF and LF bulls, in order to identify fertility markers. To our knowledge, this is the first report showing a variation in the metabolome of bull seminal plasma and spermatozoa due to cryopreservation. 


\subsection{Metabolomic Analysis of Seminal Plasma before and after Cryopreservation}

The results of the study showed that cryopreservation influences the metabolome of seminal plasma. Indeed, in the diluted seminal plasma obtained from semen cryopreserved by conventional freezing (CRY-P), some compounds were in higher amount, compared to fresh seminal plasma (F-P) among which LysoPC (0:0/18:2(9Z,12Z)) was putatively identified. LysoPC (0:0/18:2(9Z,12Z)) is a lysophospholipid characterized by the presence of one chain of linoleic acid at the C-2 position. It is formed by the hydrolysis of phosphatidylcholine by the enzyme phospholipase A2 as part of the de-acylation/re-acylation cycle. Lysophosphatidylcholine has proinflammatory properties, cell signalling functions and is known to induce sperm capacitation and acrosome reaction by increasing $\mathrm{Ca}^{2+}$ concentrations $[27,28]$. Therefore, the higher content of lysoPC detected in cryopreserved seminal plasma may at least in part account for the capacitation-like changes (cryo-capacitation) commonly observed following cryopreservation, due to increased oxidative stress [5]. In this regard, lysophosphatidylcholine has been proven to be a reliable marker of the lipid oxidation of sperm membrane [29]. This is important because cryo-capacitation results in a decrease in the reproductive lifespan of the spermatozoa [30] that may impair fertility, particularly after AI. Furthermore, a premature acrosome reaction undoubtedly causes a loss of fertility [4]. However, whether the lysophosphatidylcholine increase in CRY-P is due to the cryopreservation process or to the extender composition is not known. Therefore, the confounding effect of the extender may impede the drawing of definitive conclusions, making it difficult to hypothesize potential corrective strategies.

\subsection{Metabolomic Analysis of Spermatozoa before and after Cryopreservation}

The metabolome of spermatozoa derived from cryopreserved semen (CRY-S) did not show many differences compared to fresh spermatozoa. Indeed, only two metabolites (i.e., glycine betaine and pyro-L-glutaminyl-L-glutamine) were higher in CRY-S. This suggests that conventional semen cryopreservation is efficient to protect sperm from cryoinjuries to a certain extent. Among the two putatively identified metabolites, glycine betaine is of particular interest. Glycine betaine is a methyl group donor that functions in the normal metabolic cycle of methionine-transforming the harmful homocysteine into methionine [31]—modulates cellular responses to osmotic stress [32], acts as an osmolyte and cryoprotectant [33] and exerts antioxidant and anti-inflammatory actions [34,35]. It has been reported that betaine improves the quality of cryopreserved spermatozoa in ram [36,37] and stallions [38,39]. The supplementation of betaine to the extender improved semen quality in boar [40]. In cattle, the replacement of glycerol with betaine improved motility when spermatozoa were stored at $20{ }^{\circ} \mathrm{C}, 5{ }^{\circ} \mathrm{C}$ and $0{ }^{\circ} \mathrm{C}$ [41]. The higher amount of glycine betaine in cryopreserved spermatozoa in this study is difficult to interpret, given the limits of nontargeted metabolomics, but different hypotheses can be put forward. It is not possible to know whether this is due to reduced utilization or to increased production from choline oxidation. In favor of the first hypothesis, there is the known slowing-down of sperm metabolism induced by cryopreservation [3]. However, it is also recognized that, during dilution, cooling-freezing and thawing procedures, sperm are faced with physiological and structural challenges due to changes in osmotic balance, oxidative stress and the formation of intracellular ice crystals [3]. Therefore, we speculate that the higher levels of glycine betaine in cryopreserved spermatozoa may be more likely due to a cellular adaptative response to cryopreservation-induced oxidative and osmotic stress. Indeed, in addition to the antioxidant function [34,35], betaine is a compatible osmolyte, known to accumulate in the cell cytoplasm to prevent osmotic stress [42]. It follows that the higher amounts of the metabolite may result from the attempt of spermatozoa to counteract cryopreservation-induced stress [3]. The finding is undoubtedly interesting and hence it will be worth carrying out in vitro studies in the future to validate the hypotheses made. 


\subsection{Metabolomic Analysis of Seminal Plasma from HF and LF Bulls}

The fresh seminal plasma of HF bulls showed a different lipid profile compared to LF bulls, with an accumulation of L-acetylcarnitine, glycerol tripropanoate, 2,3-diacetoxypropyl stearate and GPC, and a depletion of lysoPC (P-16:0) and butyrylcarnitine.

Particularly interesting is the accumulation in fresh seminal plasma of HF bulls of L-acetylcarnitine, the most abundant and powerful of the acylcarnitine derivates. L-carnitine is an hydrosoluble amino acid that plays a critical role as a cofactor essential for fatty acid metabolism, by transporting fatty acids into the mitochondria for subsequent $\beta$-oxidation and hence energy generation. This process results in the esterification of L-carnitine to produce acylcarnitines, among which the L-acetylcarnitine is the most predominant. In addition, L-carnitine plays a critical role in modulating the intracellular CoA homeostasis. Carnitine is present in high concentration in the epididymis and in the spermatozoa of several species [43-46]. During transit in the epididymis, bovine sperm accumulate carnitine that is rapidly acetylated [47]. Acetylcarnitine/L-carnitine may act as a carrier system of acetyl groups between the mitochondria and cytoplasm via a translocase present on the mitochondrial membrane, playing an important role for sperm metabolism [48]. It was also reported that L-acetylcarnitine levels and a high L-acetylcarnitine:free $\mathrm{L}$-carnitine ratio in human spermatozoa were associated with motility $[49,50]$. Semen carnitine levels are also correlated with sperm concentration and progressive motility in stallions [51]. Finally, the supplementation of the semen extender with carnitine was demonstrated to improve sperm quality in cattle and buffalo [5,52]. The importance of this compound and its role on fertility are related to its antioxidant and anti-inflammatory functions [53,54], as well as to the regulative action on sperm metabolism [48]. It follows that the higher amount of L-acetylcarnitine in the fresh seminal plasma of HF bulls suggests that it can be considered a male fertility biomarker.

In addition, the triacylglycerols, glycerol tripropanoate and 2,3-diacetoxypropyl stearate, were accumulated in HF bulls. It was previously demonstrated that sperm can utilize triglycerides for their metabolism $[55,56]$. It is known that seminal plasma contains cholesterol and triacylglycerols, the latter serving as energy sources [57]. A variation in the lipid composition of seminal plasma in relation to season and semen quality was observed in cattle, with higher cholesterol levels related to better semen quality [58]. The fatty acid content of seminal plasma was correlated to semen quality in bulls and stallions $[58,59]$. Higher levels of cholesterol and triacylglycerols were associated to fertility parameters in cats [60]. In contrast, triacylglycerol levels were greater in the seminal plasma of azoospermic men [61]. Furthermore, the higher levels of GPC in the seminal plasma of HF bulls are in agreement with a previous study, revealing that seminal plasma GPC is a marker of fertility in men [62,63]. Finally, lysoPC (P-16:0), a lysophosphatidylcholine consisting of one chain of plasmalogen 16:0 at the C-1 position, was in lower amount in the seminal plasma of HF bulls. In humans, glycerophospholipids, including lysophosphatidylcholines, were found in higher concentrations in the seminal plasma of infertile men [64]. Interestingly, another lysophosphatidylcholine (i.e., lysoPC (0:0/18:2(9Z,12Z))) was higher in CRY-P compared to F-P.

Therefore, differences in the metabolites in fresh seminal plasma between HF and LF bulls allowed for the identification of potential fertility markers. However, in earlier studies, other fertility markers were identified in bovine fresh seminal plasma, such as 2-oxoglutaric acid and fructose [21], or citrate, taurine, isoleucine and leucine [15]. The differences among these studies are likely due to the different methods of analysis, as in earlier reports, gas chromatography-mass spectrometry [21] or 1H nuclear magnetic resonance were employed [15].

In this study, changes in metabolome between HF and LF bulls were also observed in diluted seminal plasma from cryopreserved semen (CRY-P). Some of the metabolites followed the same pattern described for fresh seminal plasma samples. Interestingly, the CRY-P of HF bulls also contained higher levels of GPC and lower levels of butyrylcarnitine, as in fresh seminal plasma. In addition, glycine betaine and L-carnitine contents were lower in the CRY-P of HF bulls. Metabolic relationships exist among the differentially expressed metabolites between HF and LF bulls, as GPC, glycine betaine and 
L-carnitine are involved in the same metabolic pathway. In addition, these metabolites have been proven to influence male fertility, as previously mentioned [41,52,62,63].

\subsection{Metabolomic Analysis of Spermatozoa from HF and LF Bulls}

The differences in metabolite content in fresh spermatozoa between HF and LF bulls were limited to two metabolites. Specifically, sperm from HF bulls contained higher levels of GPC and lysoPC (16:0). Glycerophosphocholines derive from unsaturated fatty acids that are the main components of the sperm membrane, essential for sperm viability and motility. It is known that sperm, during epididymal transit, incorporate GPC that is involved in sperm capacitation and metabolism [65]. Indeed, GPC may provide sperm energy substrates, such as L-glycerol 3 phosphate, also known to regulate sperm metabolism on capacitation [66]. The other identified metabolite accumulated in the sperm from HF bulls was lysoPC (16:0), a lysophospholipid with a chain of palmitic acid at the C-1 position. Phospholipids, lysophospholipids and fatty acids are implicated in several functions and play a role in sperm acrosome reaction, metabolism and motility [67]. Lysophosphatidylcholine, formed by the hydrolysis of phosphatidylcholine, a normal component of sperm plasma membrane, influences motility, capacitation and acrosome reaction $[27,28]$, contributing to membrane-fusion events during fertilization [68]. In a previous study, other metabolites, such as gamma-aminobutyric acid, carbamate, benzoic acid, lactic acid and palmitic acid, were identified as potential bull fertility markers, but a different method of analysis (i.e., GS-MS) was employed [20].

Finally, differences in cryopreserved spermatozoa between HF and LF bulls were limited to glycine betaine, whose content was lower in the former bulls. This finding is difficult to interpret, and future in vitro studies are needed to better understand the reasons. The significantly higher proportion of live spermatozoa undoubtedly accounts for a more physiological sperm metabolism in HF bulls. In addition, spermatozoa from HF bulls exhibited improved membrane integrity, assessed by the HOS test that measures the cell ability to counteract osmotic stress. This may suggest a lower capacity of spermatozoa from LF bulls to respond to the stress conditions related to cryopreservation, to which they react with a compensatory increase in glycine betaine. On the other hand, we cannot rule out that the higher amount of glycine betaine recorded in LF bulls may be due to reduced utilization, in line with the lower proportion of viable spermatozoa. It is, however, interesting to note that higher levels of glycine betaine were also recorded in cryopreserved vs. fresh spermatozoa, with the former known to exhibit lower viability [30].

\section{Conclusions}

In conclusion, cryopreservation affects bovine semen metabolome at both plasmatic and cellular compartments, resulting in the variation of metabolites that counteract oxidative stress and regulate sperm capacitation and motility. Furthermore, the metabolic profiles differ between HF and LF bulls, particularly in fresh seminal plasma, with several lipids differentially expressed, indicating the way for the identification of potential fertility biomarkers. Differences in few metabolites between HF and LF bulls are also present in cryopreserved seminal plasma and spermatozoa. Due to the high individual variability in fertilizing ability among bulls, it is thought necessary to increase the sample size in order to validate these findings in future studies.

Supplementary Materials: The following are available online at http://www.mdpi.com/2076-2615/10/6/1065/s1, Figure S1. Hierarchical clustering analysis of fresh (in blue; F-P) and cryopreserved (in red; CRY-P) seminal plasma. Differentially expressed metabolites were obtained from $t$-test $p$-value $<0.05$ and fold change $>2.0$. Figure S2. Hierarchical clustering analysis of fresh (blue; F-S) and cryopreserved (red; CRY-S) spermatozoa. Differentially expressed metabolites were obtained from $t$-test $p$-value $<0.05$ and fold change $>2.0$. Figure S3. Hierarchical clustering analysis of fresh seminal plasma for high (in red; HF) and low (in blue; LF) fertility bulls. Differentially expressed metabolites were obtained from $t$-test $p$-value $<0.05$ and fold change $>2.0$. Figure S4 . Hierarchical clustering analysis of cryopreserved seminal plasma for high (in red; HF) and low (in blue; LF) fertility bulls. Differentially expressed metabolites were obtained from $t$-test $p$-value $<0.05$ and fold change $>2.0$. Figure S5. Hierarchical clustering analysis of fresh spermatozoa for high (in red; HF) and low (in blue; LF) fertility bulls. Differentially expressed metabolites were obtained from $t$-test $p$-value $<0.05$ and fold change $>2.0$. Figure S6. 
Hierarchical clustering analysis of cryopreserved spermatozoa for high (in red; HF) and low (in blue; LF) fertility bulls. Differentially expressed metabolites were obtained from $t$-test $p$-value $<0.05$ and fold change $>2.0$.

Author Contributions: Conceptualization, B.G., F.V., G.F. and G.C.; methodology, B.G., G.F. and G.C.; validation, B.G., F.V. and G.C.; formal analysis, F.V., A.S., A.V. and V.L.; investigation, V.L. M.A.K., N.P., A.S., and A.V.; resources, B.G., F.V. and G.C.; data curation, F.V., A.S., A.V. and V.L; writing-original draft preparation, B.G., V.L. and G.F.; writing-review and editing, B.G., F.V., G.C., G.F.,V.L., M.A.K. and A.S.; visualization, B.G., V.L. and A.S.; supervision, B.G.; project administration, B.G.; funding acquisition, B.G. and G.C. All authors have read and agreed to the published version of the manuscript.

Funding: This research was funded by the project: Development of innovative pro-fertility products in bovine frozen semen, Nuproferb". PSR Regione Umbria 2014-2020.

Conflicts of Interest: The authors declare no conflict of interest.

\section{References}

1. García-Vázquez, F.A.; Gadea, J.; Matás, C.; Holt, W.V. Importance of sperm morphology during sperm transport and fertilization in mammals. Asian J. Androl. 2016, 18, 844-850. [CrossRef] [PubMed]

2. Morrell, J.M.; Nongbua, T.; Valeanu, S.; Verde, I.L.; Lundstedt-Enkel, K.; Edman, A.; Johannisson, A. Sperm quality variables as indicators of bull fertility may be breed dependent. Anim. Reprod. Sci. 2017, 185, 42-52. [CrossRef]

3. Ugur, M.R.; Abdelrahman, A.S.; Evans, H.C.; Gilmore, A.A.; Hitit, M.; Arifiantini, R.I.; Purwantara, B.; Kaya, A.; Memili, E. Advances in Cryopreservation of Bull Sperm. Front. Veter-Sci. 2019, 6, 268. [CrossRef] [PubMed]

4. Cormier, N.; Sirard, M.; Bailey, J.L. Premature capacitation of bovine spermatozoa is initiated by cryopreservation. J. Androl. 1997, 18, 461-468. [PubMed]

5. Longobardi, V.; Zullo, G.; Salzano, A.; De Canditiis, C.; Cammarano, A.; De Luise, L.; Puzio, M.V.; Neglia, G.; Gasparrini, B. Resveratrol prevents capacitation-like changes and improves in vitro fertilizing capability of buffalo frozen-thawed sperm. Theriogenology 2017, 88, 1-8. [CrossRef] [PubMed]

6. Lone, S.A.; Sinha, R.; Rahim, A.; Ganaie, B.A.; Singh, A.; Shah, N. Spermatozoa molecules in relation to bulls fertility. Iran. J. Appl. Anim. Sci. 2017, 7, 371-375.

7. Cancel, A.M.; Chapman, D.A.; Killian, G.J. Osteopontin is the 55-kilodalton fertility-associated protein in Holstein bull seminal plasma. Biol. Reprod. 1997, 57, 1293-1301. [CrossRef]

8. Brown, K.I.; Crabo, B.G.; Graham, E.F.; Pace, M.M. Some factors affecting loss of intracellular enzymes from spermatozoa. Cryobiology 1971, 8, 220-224. [CrossRef]

9. Roychoudhury, P.N.; Gowda, H.C.; Pareek, P.K. Effect of Different Glycerol Levels on the Release of Glutamic Oxaloacetic Transaminase (GOT) from Deep Frozen Ram Spermatozoa. Andrologia 1975, 7, 211-215. [CrossRef]

10. Ollero, M.; Bescós, O.; Cebrián-Pérez, J.A.; Muiño-Blanco, T. Loss of plasma membrane proteins of bull spermatozoa through the freezing-thawing process. Theriogenology 1998, 49, 547-555. [CrossRef]

11. Al Naib, A.; Hanrahan, J.; Lonergan, P.; Fair, S. In vitro assessment of sperm from bulls of high and low field fertility. Theriogenology 2011, 76, 161-167. [CrossRef] [PubMed]

12. Dogan, S.; Mason, M.C.; Govindaraju, A.; Belser, L.; Kaya, A.; Stokes, J.; Rowe, D.; Memili, E. Interrelationships Between Apoptosis and Fertility in Bull Sperm. J. Reprod. Dev. 2013, 59, 18-26. [CrossRef] [PubMed]

13. Mocé, E.; Graham, J. In vitro evaluation of sperm quality. Anim. Reprod. Sci. 2008, 105, 104-118. [CrossRef] [PubMed]

14. Kovac, J.R.; Pastuszak, A.W.; Lamb, D.J. The use of genomics, proteomics, and metabolomics in identifying biomarkers of male infertility. Fertil. Steril. 2014, 99, 998-1007. [CrossRef]

15. Kumar, A.; Kroetsch, T.; Blondin, P.; Anzar, M. Fertility-associated metabolites in bull seminal plasma and blood serum: 1H nuclear magnetic resonance analysis. Mol. Reprod. Dev. 2015, 82, 123-131. [CrossRef]

16. Muñoz, M.; Uyar, A.; Correia, E.; Diez, C.; Fernández-González, A.; Caamaño, J.N.; Trigal, B.; Carrocera, S.; Seli, E.; Gómez, E.; et al. Non-invasive assessment of embryonic sex in cattle by metabolic fingerprinting of in vitro culture medium. Metabolomics 2013, 10, 443-451. [CrossRef]

17. Oliver, S.G.; Winson, M.K.; Kell, D.B.; Baganz, F. Systematic functional analysis of the yeast genome. Trends Biotechnol. 1998, 16, 373-378. [CrossRef] 
18. Fiehn, O. Metabolomics-the link between genotypes and phenotypes. Plant Mol. Biol. 2002, 48, $155-171$. [CrossRef]

19. Dunn, W.; Bailey, N.J.C.; Johnson, H.E. Measuring the metabolome: Current analytical technologies. Analyst 2005, 130, 606-625. [CrossRef]

20. Menezes, E.B.; Velho, A.L.C.; Santos, F.; Dinh, T.; Kaya, A.; Topper, E.; Moura, A.A.; Memili, E. Uncovering sperm metabolome to discover biomarkers for bull fertility. BMC Genom. 2019, 20, 714. [CrossRef]

21. Velho, A.L.C.; Menezes, E.; Dinh, T.; Kaya, A.; Topper, E.; Moura, A.A.; Memili, E. Metabolomic markers of fertility in bull seminal plasma. PLoS ONE 2018, 13, e0195279. [CrossRef] [PubMed]

22. Fernández-Gago, R.; Domínguez, J.C.; Martinez-Pastor, F. Seminal plasma applied post-thawing affects boar sperm physiology: A flow cytometry study. Theriogenology 2013, 80, 400-410. [CrossRef] [PubMed]

23. Frederiksen, H.; Jørgensen, N.; Andersson, A.-M. Parabens in urine, serum and seminal plasma from healthy Danish men determined by liquid chromatography-tandem mass spectrometry (LC-MS/MS). J. Expo. Sci. Environ. Epidemiol. 2011, 21, 262-271. [CrossRef] [PubMed]

24. Talevi, R.; Barbato, V.; Fiorentino, I.; Braun, S.; Longobardi, S.; Gualtieri, R. Protective effects of in vitro treatment with zinc, d-aspartate and coenzyme q10 on human sperm motility, lipid peroxidation and DNA fragmentation. Reprod. Biol. Endocrinol. 2013, 11, 81. [CrossRef]

25. Rubessa, M.; Boccia, L.; Campanile, G.; Longobardi, V.; Albarella, S.; Tateo, A.; Zicarelli, L.; Gasparrini, B. Effect of energy source during culture on in vitro embryo development, resistance to cryopreservation and sex ratio. Theriogenology 2011, 76, 1347-1355. [CrossRef]

26. Chen, X.; Hu, C.; Dai, J.; Chen, L. Metabolomics Analysis of Seminal Plasma in Infertile Males with Kidney-Yang Deficiency: A Preliminary Study. Evid. Based Complement Altern. Med. 2015, 2015, 892930. [CrossRef]

27. Wheeler, M.B.; Seidel, G.E. Capacitation of bovine spermatozoa by lysophospholipids and trypsin. Gamete Res. 1989, 22, 193-204. [CrossRef]

28. Kyono, K.; Hoshi, K.; Saito, A.; Tsuiki, A.; Hoshiai, H.; Suzuki, M. Effects of phospholipase A2, lysophosphatidyl choline, and fatty acid on the acrosome reaction of human spermatozoa. Tohoku J. Exp. Med. 1984, 144, 257-263. [CrossRef]

29. Nimptsch, A.; Pyttel, S.; Paasch, U.; Mohr, C.; Heinrich, J.-M.; Schiller, J. A MALDI MS Investigation of the Lysophosphatidylcholine/Phosphatidylcholine Ratio in Human Spermatozoa and Erythrocytes as a Useful Fertility Marker. Lipids 2014, 49, 287-293. [CrossRef]

30. Castro, L.S.; Hamilton, T.R.D.S.; Mendes, C.M.; Nichi, M.; Barnabe, V.; Visintin, J.A.; Assumpção, M.E. Sperm cryodamage occurs after rapid freezing phase: Flow cytometry approach and antioxidant enzymes activity at different stages of cryopreservation. J. Anim. Sci. Biotechnol. 2016, 7, 17. [CrossRef]

31. Kidd, M.; Ferket, P.; Garlich, J. Nutritional and osmoregulatory functions of betaine. World Poult. Sci. J. 1997, 53, 125-139. [CrossRef]

32. Petronini, P.G.; De Angelis, E.M.; Borghetti, P.; Borghetti, A.F.; Wheeler, K.P. Modulation by betaine of cellular responses to osmotic stress. Biochem. J. 1992, 282, 69-73. [CrossRef] [PubMed]

33. Lindeberg, H.; Kurten, A.; Koskinen, E.; Katila, T. Freezing of stallion semen with addition of glycine betaine. J. Vet. Med. 1999, 46, 87-90. [CrossRef] [PubMed]

34. D’Onofrio, N.; Balestrieri, A.; Neglia, G.; Monaco, A.; Tatullo, M.; Casale, R.; Limone, A.; Balestrieri, M.L.; Campanile, G. Antioxidant and Anti-Inflammatory Activities of Buffalo Milk $\delta$-Valerobetaine. J. Agric. Food Chem. 2019, 67, 1702-1710. [CrossRef]

35. Attia, Y.A.; El-Naggar, A.S.; Abou-Shehema, B.M.; Abdella, A.A. Effect of Supplementation with Trimethylglycine (Betaine) and/or Vitamins on Semen Quality, Fertility, Antioxidant Status, DNA Repair and Welfare of Roosters Exposed to Chronic Heat Stress. Animals 2019, 9, 547. [CrossRef]

36. Sánchez-Partida, L.G.; Setchell, B.P.; Maxwell, W.M.C. Effect of compatible solutes and diluent composition on the post-thaw motility of ram sperm. Reprod. Fertil. Dev. 1998, 10, 347-357. [CrossRef]

37. Sanchez-Partida, L.; Maxwell, W.; Paleg, L.; Setchell, B. Proline and glycine betaine in cryoprotective diluents for ram spermatozoa. Reprod. Fertil. Dev. 1992, 4, 113-118. [CrossRef]

38. Koskinen, E.; Junnila, M.; Katila, T.; Soini, H. A Preliminary Study on the Use of Betaine as a Cryoprotective Agent in Deep Freezing of Stallion Semen. J. Vet. Med. 1989, 36, 110-114. [CrossRef]

39. Trimeche, A.; Yvon, J.M.; Vidament, M.; Palmer, E.; Magistrini, M. Effects of glutamine, proline, histidine and betaine on post-thaw motility of stallion spermatozoa. Theriogenology 1999, 52, 181-191. [CrossRef] 
40. Lugar, D.W.; Krom, W.A.; Mings, P.D.; Stewart, K.R. Effects of supplemental betaine to semen extenders on semen quality in boars. Transl. Anim. Sci. 2018, 2, 195-204. [CrossRef]

41. Zhang, B.R.; Buhr, M.; Kroetsch, T.; Leibo, S.P. Glycine betaine improves survival of fresh bovine spermatozoa. Reprod. Fertil. Dev. 2001, 13, 187-192. [CrossRef] [PubMed]

42. Lipiński, K.; Szramko, E.; Jeroch, H.; Matusevicius, P. Effects of Betaine on Energy Utilization in Growing Pigs-A Review. Ann. Anim. Sci. 2012, 12, 291-300. [CrossRef]

43. Ruiz-Pesini, E.; Alvarez, E.; Enríquez, J.A.; López-Pérez, M.J. Association between seminal plasma carnitine and sperm mitochondrial enzymatic activities. Int. J. Androl. 2001, 24, 335-340. [CrossRef] [PubMed]

44. Brooks, D.E. Carnitine, acetylcarnitine and the activity of carnitine acyltransferases in seminal plasma and spermatozoa of men, rams and rats. J. Reprod. Fertil. 1979, 56, 667-673. [CrossRef]

45. Casillas, E.R. The distribution of carnitine in male reproductive tissues and its effect on palmitate oxidation by spermatozoal particles. Biochim. Biophys. Acta 1972, 280, 545-551. [CrossRef]

46. Casillas, E.R.; Villalobos, P.; Gonzales, R. Distribution of carnitine and acylcarnitine in the hamster epididymis and in epididymal spermatozoa during maturation. J. Reprod. Fertil. 1984, 72, 197-201. [CrossRef]

47. Casillas, E.R. Accumulation of carnitine by bovine spermatozoa during maturation in the epididymis. J. Biol. Chem. 1973, 248, 8227-8232.

48. Jeulin, C.; Lewin, L. Role of free L-carnitine and acetyl-L-carnitine in post-gonadal maturation of mammalian spermatozoa. Hum. Reprod. Updat. 1996, 2, 87-102. [CrossRef]

49. Golan, R.; Weissenberg, R.; Lewin, L.M. Carnitine and acetylcarnitine in motile and immotile human spermatozoa. Int. J. Androl. 1984, 7, 484-494. [CrossRef]

50. Johansen, L.; Bohmer, T. Motility related to the presence of carnitine and carnitine/acetylcarnitine in human spermatozoa. Int. J. Androl. 1979, 2, 202-210. [CrossRef]

51. Stradaioli, G.; Lakamy, S.; Zelli, R.; Chiodi, P.; Monaci, M. Effect of L-carnitine administration on the seminal characteristics of oligoasthenospermic stallions. Theriogenology 2004, 62, 761-777. [CrossRef] [PubMed]

52. Bucak, M.N.; Tuncer, P.B.; Sarı̈zkan, S.; Başpınar, N.; Taşpınar, M.; Çoyan, K.; Bilgili, A.; Akalın, P.P.; Büyükleblebici, S.; Aydos, S.; et al. Effects of antioxidants on post-thawed bovine sperm and oxidative stress parameters: Antioxidants protect DNA integrity against cryodamage. Cryobiology 2010, 61, 248-253. [CrossRef] [PubMed]

53. Zou, Y.-J.; Yang, J.; Chang, S.; Xu, W.-M.; Yin, T.-L.; Long, W. Acetyl-L-carnitine: An effective antioxidant against cryo-damage on human spermatozoa with asthenospermia. J. Huazhong Univ. Sci. Technol. Med. Sci. 2017, 37, 915-921. [CrossRef]

54. Truong, T.; Gardner, D.K. Antioxidants improve IVF outcome and subsequent embryo development in the mouse. Hum. Reprod. 2017, 32, 2404-2413. [CrossRef] [PubMed]

55. Montagnon, D.; Valtat, B.; Vignon, F.; Koll-Back, M.H. Secretory proteins of human seminal vesicles and their relationship to lipids and sugars. Andrologia 1990, 22, 193-205. [CrossRef] [PubMed]

56. Vignon, F.; Koll-Back, M.H.; Clavert, A.; Cranz, C. Lipid Composition of Human Seminal Plasma. Arch. Androl. 1989, 22, 49-53. [CrossRef]

57. Beer-Ljubic, B.; Aladrovic, J.; Marenjak, T.S.; Laskaj, R.; Majić-Balić, I.; Milinković-Tur, S. Cholesterol concentration in seminal plasma as a predictive tool for quality semen evaluation. Theriogenology 2009, 72, 1132-1140. [CrossRef]

58. Argov, N.; Sklan, D.; Zeron, Y.; Roth, Z. Association between seasonal changes in fatty-acid composition, expression of VLDL receptor and bovine sperm quality. Theriogenology 2007, 67, 878-885. [CrossRef]

59. Brinsko, S.P.; Love, C.; Bauer, J.; MacPherson, M.; Varner, D. Cholesterol-to-phospholipid ratio in whole sperm and seminal plasma from fertile stallions and stallions with unexplained subfertility. Anim. Reprod. Sci. 2007, 99, 65-71. [CrossRef]

60. García, M.F.; Favre, R.N.; Stornelli, M.C.; Rearte, R.; Mitacek, M.C.G.; De La Sota, R.L.; Stornelli, M.A. Relationship between semen quality and seminal plasma cholesterol, triacylglycerols and proteins in the domestic cat. J. Feline Med. Surg. 2019, 1-8. [CrossRef]

61. Sebastian, S.M.; Selvaraj, S.; Aruldhas, M.M.; Govindarajulu, P. Pattern of neutral and phospholipids in the semen of normospermic, oligospermic and azoospermic men. J. Reprod. Fertil. 1987, 79, 373-378. [CrossRef] [PubMed]

62. Deepinder, F.; Chowdary, H.T.; Agarwal, A. Role of metabolomic analysis of biomarkers in the management of male infertility. Expert Rev. Mol. Diagn. 2007, 7, 351-358. [CrossRef] [PubMed] 
63. Gupta, A.; Mahdi, A.A.; Ahmad, M.K.; Shukla, K.K.; Jaiswer, S.P.; Shankhwar, S.N. 1H NMR spectroscopic studies on human seminal plasma: A probative discriminant function analysis classification model. J. Pharm. Biomed. Anal. 2011, 54, 106-113. [CrossRef] [PubMed]

64. Rivera-Egea, R.; Garrido, N.; Sota, N.; Meseguer, M.; Remohí, J.; Dominguez, F. Sperm lipidic profiles differ significantly between ejaculates resulting in pregnancy or not following intracytoplasmic sperm injection. J. Assist. Reprod. Genet. 2018, 35, 1973-1985. [CrossRef]

65. Mitra, J.; Chowdhury, M. Association of glycerylphosphorylcholine with human sperm and effect of capacitation on their metabolism. Reprod. Fertil. Dev. 1994, 6, 679-685. [CrossRef]

66. Chowdhury, M.; Mitra, J. Glycerylphosphorylcholine (GPC) diesterase related alterations in the oxygen consumption profile of rat spermatozoa in differing functional states. Int. J. Androl. 1992, 15, 345-354. [CrossRef]

67. Mann, T.; Lutwak-Mann, C. Male Reproductive Function and the Composition of Semen: General Considerations. In Male Reproductive Function and Semen; Springer: Berlin/Heidelberg, Germany, 1981; pp. 1-37.

68. Riffo, M.; Párraga, M. Role of phospholipase A2 in mammalian sperm-egg fusion: Development of hamster oolemma fusibility by lysophosphatidylcholine. J. Exp. Zool. 1997, 279, 81-88. [CrossRef]

(C) 2020 by the authors. Licensee MDPI, Basel, Switzerland. This article is an open access article distributed under the terms and conditions of the Creative Commons Attribution (CC BY) license (http://creativecommons.org/licenses/by/4.0/). 